\title{
A leap of faith? Trust in the police among immigrants in England and Wales
}

Ben Bradford, Centre for Criminology, University of Oxford*

Elise Sargeant, Institute for Social Science Research, University of Queensland

Kristina Murphy, Griffith Criminology Institute, Griffith University

Jonathan Jackson, Methdodology Department, London School of Economics

\begin{abstract}
It is often assumed that immigrants in countries such as the UK will report lower levels of trust in the police. Immigrant communities are thought 'difficult to police', and minority groups frequently experience problematic relationships with police. Yet, there has been little empirical investigation of this issue in the UK. In this paper data from the Crime Survey of England and Wales (CSEW) are used to explore the relationship between immigration and trust in the police. Results suggest that trust is higher among immigrants than among the UK-born population, although there is important variation by time since arrival and experience of policing. Trust in the police is also higher in neighbourhoods that have more immigrants. The paper concludes with some reflection on the nature of trust in the police.
\end{abstract}

Key words: Trust, police, immigration, CSEW.

Funding: This work was supported by the Economic and Social Research Council [grant number ES/L011611/1].

* Corresponding author: Centre for Criminology, University of Oxford, Manor Road Building, Manor Road, Oxford OX1 2UQ. Email: ben.bradford@crim.ox.ac.uk. Tel: +44(0)1865 281927. Fax +44(0)1865 281924. 
Much academic, political and cultural discourse suggests that immigrants to a country like the United Kingdom will, on average, report less trust in criminal justice institutions than their native-born counterparts. The negative experiences of many immigrants, particularly those from visible ethnic minority groups, at the hands of police and other criminal justice actors (e.g. Pantazis and Pemberton 2009; Parmar 2011; Delsol \& Shiner, 2015) are of course relevant issues. There is also a wider view that culturally dissimilar individuals or groups are unable to develop the social bonds upon which trust relies (Goodhart 2014) and, moreover, that immigration and the diversity it invokes affect the views of both newcomers and those already resident in a particular context (Putnam 2007). As Sturgis et al. (2014: 1287) note, there is an "increasingly consensual view within academic and policy circles that ethnically diverse communities are characterized by distrust, low levels of social cohesion and disputes regarding the equitable provision of public goods".

Some theories of trust appear to support these assertions. Hardin (2006) argues that trust judgments are generally made about those with whom we have existing relationships; it follows that immigrants will trust the police less, in part because they have fewer or weaker relationships with relevant actors, at least in the initial period after migration. Other theories of trust provide more mixed messages, though. Uslaner (2002) suggests that trust is rooted in a particular moral understanding of the world. Like any group of people some immigrants will be 'generalized' trustors, who believe "most people can be trusted" (Uslaner 2008: 726), but others will be 'particularized' trustors who trust only people they perceive as similar to themselves. If they tend to draw tight boundaries around their community, recent immigrants in particular may invest less trust in the police. A third theory characterizes trust as a complexity-reducing mechanism (Giddens 1991) - something that provides reassurance and allows action under the conditions of late modernity. Here, immigrants might be on average higher in trust, something that may indeed have facilitated the act of migration in the first place (Maxwell 2010).

In this paper we use these contrasting theories to frame an analysis of trust in the police among immigrants living in England and Wales. Our aims are threefold. First, we seek to explore variation in trust among migrants versus non-migrants. Do immigrants trust the police less, on average, because they have little knowledge of and tenuous relationships with police? Do they trust more (perhaps because they are predisposed to trust) or is there, in fact, no relationship between immigration status and trust in police?

Second, we consider variation in trust among immigrants, asking, what factors might shape levels of trust and changes in trust over time? Most theories of trust stress that personal experience shapes trust judgments. How does this play out in the relationship between police and immigrants, particularly given the long history of problematic relations between police and many immigrant communities? Is trust in the police lower among immigrants who have lived in the UK for longer? If so, can this be explained by negative contacts they have had with the police?

Third, we examine the possible effect of immigration into local areas on trust in the police among residents. A common assumption is that high levels of 
immigration can undermine the general populace's trust in social institutions, yet Sturgis et al's (2014) study - along with research on the relationship between immigration and crime (e.g. Sampson 2008) - suggests a more complex relationship between immigrant concentration and public perceptions of the police. This issue is important in any investigation of trust in the police since it speaks to the role of neighbourhood context. Do immigrants trust the police more or less when they live in a neighbourhood that has a relatively high concentration of immigrants? To this we extend the focus across the whole population. Do non-migrants trust the police more or less when they live in a neighbourhood that has a relatively high concentration of immigrants?

The paper proceeds as follows. After first outlining the extant research on the relationship between immigration and trust in the police, we move on to discuss the three theories of trust noted above and explore what they might imply in the present context. After next describing our data and methods we present results from analysis of the Crime Survey of England and Wales (CSEW). We conclude by exploring what our results might mean in terms of the conceptualization and measurement of trust in the police.

\section{Migration and trust in police}

While much research has considered trust in the police among ethnic minority groups (e.g. Tyler, 2005; Murphy and Cherney, 2012; Sharp and Atherton 2007), there has been much less consideration given to levels of trust among immigrants a somewhat surprising situation given the level of political and academic debate around immigration over recent decades.

There are, of course, exceptions. Some studies suggest there is no consistent relationship between migration status and trust. Working with a British sample, Heath et al. (2011) found that levels of trust in the police were broadly similar across native-born and first generation immigrant populations, but significantly lower among second generation immigrants from ethnic minority groups. Röder and Mühlau (2012) report similar findings from a cross-national European study. By contrast, other research suggests a negative association. Piatkowska (2015) used data from the World Values Survey to show that, across 50 countries, first generation immigrants had slightly lower levels of confidence in the police than non-immigrants, while Davis and Mateu-Gelabert (2000) found that immigrants in New York were more critical of police than their non-immigrant counterparts.

Yet other studies suggest a positive association. Nannestad et al. (2014) compared institutional trust, including trust in the police, across four immigrant groups living in Denmark (Turks, Pakistanis, Bosnians and Serbian/Montenegrins) with levels of trust among people in the same countries of origin. They found that trust in the police was substantially higher among immigrants living in Denmark than it was among those living in the relevant country of origin. Finally, Davis and Hendricks (2007) found that Hispanic and Asian immigrants in Seattle were less critical of police than non-immigrants.

Current research therefore presents rather discordant findings. However, many of these studies have been hindered by a lack of criminologically relevant variables - most importantly, contact with police officers and the characteristics of 
the areas in which people live, which have consistently been shown to be the most important predictors of trust in the police (Brown and Benedict 2002). We employ here CSEW data that has two significant advantages for this research context: (a) it includes measures of contact with the police and the characteristics of respondent's neighbourhoods; and (b) it allows for a multi-level analysis that disentangles individual- and neighbourhood-level variation.

\section{Three theories of trust}

What does it mean to trust the police? How is it that people come to place trust in this particular institution, and why do some fail to do so? In this paper we draw on three different conceptualizations of trust: the relational notion associated with theorists such as Russell Hardin (2006); the value-based notion proposed by Eric Uslaner (2002); and Anthony Giddens' (1991) concept of trust as a complexity reducing mechanism. All three theories coalesce around the idea that trust comprises perceptions of, or tacit knowledge (Polanyi 1967) about, competency or effectiveness, on the one hand, and of right intentions, on the other. Yet each suggests different dynamics of trust, with the way trust is formed and reproduced varying significantly across the three accounts.

The idea that trust comprises perceptions of the effectiveness and intentions of others is most clearly stated by Hardin, who locates trust in our knowledge of the trustworthiness of others. Trust is cognitive, since it depends on judgments about the character of the potentially trusted other: "to say we trust you means we believe you have the right intentions toward us and that you are competent to do what we trust you to do" (Hardin 2006: 17). The trustor does not choose to trust, rather, relevant knowledge of (beliefs about) the abilities and intentions of the trustee comprise trust.

For Hardin, because trust emerges when the trustor has relevant knowledge about the trustee this pre-supposes a relationship between the two: trust is an emergent property of specific social relationships. This has two important implications. First, the relationship should exist in a social context about which the trustor has some experience or knowledge, without which they would not be able to judge what constitutes competency and appropriate intentions. Hardin stresses the importance of "standard, recurring contexts" (Hardin 2006: 3), within which the potential trustor learns through experience about the abilities and intentions of the potential trustee. Direct contacts with potential trust objects are therefore important moments upon which subsequent trust judgments are based - an idea that resonates strongly with research that demonstrates a strong association between personal contact and public trust in police (Skogan 2006).

Second, trust is formed and maintained because both parties have an interest in maintaining a relationship with the other. The trustor has a need to trust the trustee that is inevitably future-oriented; trust is bound up with judgments about the likely future behaviour of others. Equally, the trustee must know something of the trustor to be able to anticipate their needs and priorities, and communicate the right intentions in relation to their interests. The trustee must also have an interest in maintaining the relationship between the two, since without such a need they would have no reason to demonstrate competency and right 
intentions. Trust is thus based on the pre-existing relationships both parties imagine will continue into the future.

Hardin is concerned primarily with trust between individual actors in limited networks, and he appears to concur with the argument that individuals cannot really trust 'abstract' institutions such as the police "because they cannot have the knowledge that it would take to define trust" (Hardin 2006: 18, quoting Montinola 2004). Yet, the relational notion of trust he develops also seems relevant when considering public trust in the police. The police comprise a visible presence in the lives of many citizens that is not abstract or faceless, but rather associated with a variety of more or less imagined, but nevertheless 'real', social personae (such as, most famously, the 'bobby on the beat'). Equally, police in democratic states rely on the trust of citizens to a significant degree. At the very least, their job is made much harder when trust is low. Police therefore 'encapsulate' (Hardin 2006: 8) the interests of citizens within their own interests (which is not to claim, of course, that police do not frequently behave in ways that undermine public trust).

Uslaner (2002) takes a different view of trust formation. Starting from a critique of the theory of trust proposed by Hardin, he posits that trust is first and foremost a moral value based not on personal experience but on a particular view of life. While Hardin's notion of trust revolves around concrete forms of knowledge, Uslaner stresses much more general perceptions or beliefs that people have (or do not have) about the good intentions of others. These perceptions emerge as the corollary of a viewpoint, unevenly distributed across a given population, that other people are worthy of trust because they:

"share your fundamental moral values and therefore should be treated as you would wish to be treated by them. The values they share may vary from person to person. What matters is a sense of connection with others because you see them as members of your community whose interests must be taken seriously" (Uslaner 2002: 18).

In other words, we choose to believe that people 'like us' have the right intentions towards us because we feel a connection to them and see ourselves reflected in them.

Uslaner has recently been viewed as the main proponent of a cultural perspective that argues trust is developed in childhood via parental socialization and remains largely stable throughout life and over generations (Dinesen 2013: 115). Trust here takes on a heritable quality, albeit that transmission is envisaged as being primarily social rather than genetic (we are brought up to trust if our parents were also brought up to trust). What is interesting in the current context is Uslaner's development of this core idea. On the one hand, a measure of fundamental similarity between trustor and trustee is supposed, enabling the former to imagine the latter as part of their community. A sense of shared community is also thought to create the space for 'regular expectations' of the behaviour of others to take shape; an idea that links Uslaner's notion of trust to Hardin's. On the other hand, Uslaner stresses that moralistic trust is based on a general expectation of the goodwill of others (2002: 18). This aspect of trust rests simply on a sense of general shared humanity, and it does not require, for example, a pre-existing community. An 
important implication here is that personal experience of a potential trust object is relatively less important, since trust is based on views of intrinsic moral worthiness rather than experienced performance.

Uslaner also draws a strong distinction between particularized and generalized trustors, where the difference between the two groups is premised on community boundaries. Particularized trustors draw their boundaries tight, including only family and immediate friends in their community: only these people are seen to be worthy of trust. Generalized trustors, by contrast, draw the boundaries widely. They include many more, and even all, people in their community, and are motivated to trust a wider range of individuals and corporate actors. These ideas have similarities to the Group Value and the Group Engagement Models of procedural justice, which are frequently employed to understand citizens' attitudes toward police (e.g. Tyler and Huo 2002). These models state that when people feel part of the group that an authority represents they are more likely to trust its motives, and that this sense of identification can be bolstered by the use of fair treatment and procedures. If an immigrant's trust is particularized to their own ethnic group or country of origin, and/or they do no feel part of the society they migrate to, they may lack trust in the motives of authorities representing a wider group of which they do not feel membership.

Giddens presents a third distinct theory of trust. In Modernity and SelfIdentity (1991), he positions trust as a characteristic of the individual that enables people living under the complexity of the late modern condition to 'bracket out' this complexity and experience the world as understandable, coherent and manageable. Trust provides for a sense of "ontological security" and is an aspect of the individual's "practical consciousness" (Giddens 1991: 36), which allows them to act within highly complex social situations. The capacity to trust in these terms is linked explicitly to the pre-eminence of expert systems in late modernity. These are forms of technical knowledge and practice that have "validity independent of the practitioners and clients that make use of them" (ibid: 18), and which channel and make useful the vastly increased store of human knowledge and potential in a process that relies on people's willingness to trust the system rather than the individual. The resonance here with policing and the provision of security is obvious. Behaving as if we 'know for sure' institutions of police and justice can provide a basic sense of security and the possibility of justice. Placing trust in police irrespective of whether we have knowledge of individual police officers reassures and enables action because such trust motivates a sense that help and support can be invoked if needed. This is not to claim that everyone trusts the police, but merely that the condition of late modernity makes such trust useful and enabling.

Two further aspects of Giddens' concept of trust are pertinent to our discussion. First, he insists trust cannot be based on full knowledge but, rather, "presumes a leap to commitment, a quality of 'faith' which is irreducible" (ibid: 19). David Smith (2007: 299-300; see also Möllering 2006) has made precisely this point when discussing the formation of public trust in the police: we are motivated to make the leap of faith to trust since "we want to believe, if possible, that we live in a society where most people trust the police ... because a society in which most people trust the police will be far more secure than any other". 
Second, like Uslaner, Giddens locates a significant portion of individuals' propensity to trust in their early socialization and as a deeply held character trait. Drawing on the psychoanalysis of DW Winnicot, he argues that: "The trust which the child, in normal circumstances, vests in its caretakers ... can be seen as a sort of emotional inoculation against existential anxieties - a protection against future threats and dangers" (ibid. 39), and that this trust carries forward into adult life.

\section{Immigrants' trust in police}

What does all this mean for likely levels of trust in the police among immigrants? Hardin's model suggests a net negative association between immigration and trust in police because it envisages that migrants would need to build up a 'knowledge bank' about policing before trust (or conversely distrust) could emerge. In the absence of concrete experience, and all else being equal, recent immigrants should be less willing to answer in the affirmative questions concerning the ability and intentions of the police. Furthermore, although the passing of time and the generation of familiarity might allow trust to emerge, the often-cited problematic relationships between police and immigrant/minority communities, and the negative experiences many people from minority groups have of police, may ensure that trust never develops or that active distrust emerges.

Uslaner's account provides rather mixed messages. The concept of moralistic trust suggests that some immigrants will be predisposed to trust the police. Indeed it is possible they will be higher, on average, in this form of trust: believing unknown others have the right intentions towards you may be one factor motivating or enabling migration. But the importance of shared community in Uslaner's model suggests that migrants would need some time in their new home before the boundaries of moral community expand to include police and, again, this may never happen for the reasons outlined above.

Gidden's account of trust also provides mixed messages. On the one hand, many immigrants have already made a 'leap of faith' when moving to a new country. As noted above, by dint of their migration they have demonstrated a relatively high level of trust, particularly in terms of the ability of the institutional systems in their new home will support and enable them (Maxwell 2010). This would suggest relatively high levels of trust in police and other criminal justice actors as mechanisms for the provision of security. Yet, on the other hand, Giddens also suggests, like Hardin, that trust can be based on rational calculation, not least because of the intrinsic reflexivity of late modernity - we are continuously reflecting on and reassessing our experiences and relationships with others. Immigrants, like others, will draw on their experiences of police when forming their trust judgments; and this experience is not always a good one.

Three further points are worthy of comment. First, trust in the police is likely to vary as a function of the length of time an immigrant has been in the destination country. Levels of trust among immigrants may gradually align with those among the non-migrant population, as knowledge of and contact with police equalizes with the non-migrant population and as the boundaries of individuals' moral communities shift and expand. If immigrants start with lower trust and have bad experiences with police, however, their social distance from the non-migrant 
population may grow. There is also likely to be an important interaction with ethnicity here. In as much as they receive differential policing, the experiences of different minority groups may shape the speed and end-point of any acculturation process.

Second, factors associated with the immigrant's country of origin will be important. Nannestad et al. (2014), for example, show that trust in the police is higher among immigrants in Denmark than it is among non-migrants in relevant countries of origin. They conclude this can be explained by the better institutional framework in Denmark compared with Turkey, Pakistan and the former Yugoslavia - something that may enable the 'leap of faith' to trust police (see also Röder and Mühlau 2012). However, it could equally be the case that immigrants 'import' low levels of trust developed in their countries of origin to their final destination (Mutsaers 2014; Uslaner 2008). Third, the context into which migrants move will also be relevant. Initial expectations of police among immigrants may be shaped by factors as diverse as the cultural image of police, the conditions of democracy, and the strength of the rule of law in the destination country.

To be clear at the outset, we cannot directly address factors relating to origin or destination countries with the data available for this paper, but it is important to note their relevance, and we return to this issue in the conclusion.

\section{The wider effect of immigration on trust}

Thus far we have concentrated on the association between immigration and trust in police at the individual level. However, there is a common assumption that high levels of immigration (often associated or conflated with high levels of diversity) into a local area can affect trust judgments not only of the immigrant population but also those of non-migrant residents (Sturgis et al. 2014). Indeed this idea flows directly from some of the arguments above, particularly those relating to the importance of stability and moral community in shaping trust. Immigration is, at the aggregate level, a marker and instance of change, reducing predictability and, on some accounts, weakening the bonds between people because it introduces greater social variety into local contexts. This is an argument associated with the work of Robert Putnam (2007). He posits that immigration - because it increases diversity is likely to "foster out-group distrust and in-group solidarity" (ibid: 142), thus undermining social capital and cohesion and weakening the bonds between individuals and institutions. It has been claimed, for example, that immigration depresses support for the welfare state (Crepaz 2008), while several studies have found a negative association between perceptions of immigration and levels of political and social trust (e.g. Alesina and La Ferrera 2002; McLaren 2010). Opinions of the police, important representatives of the community at national and local levels (Girling et al. 2000; Jackson et al. 2013), may be caught up in these processes - trust in the police may suffer when a community seems unstable.

Yet, there is significant countervailing evidence here. Social cohesion seems to be higher in more diverse areas of London (Sturgis et al. 2014), and crime, often associated with social cohesion and collective efficacy, is also often negatively correlated with immigration (e.g. MacDonald et al. 2013; Sampson 2008). This may be so because immigration 'revitalizes' local areas by providing new social 
networks, social entrepreneurship and perhaps simply more people (Thomas 2011). Importantly, UK studies have shown that trust in the police tends to be higher when social cohesion is high (Jackson et al. 2013), and higher among people who experience high levels of social cohesion in their community (Jackson and Sunshine 2007). It may therefore be that immigration into an area actually increases trust in the police.

In this paper we explore these issues by using multi-level regression modeling to: (a) compare trust in the police among immigrants and non-immigrants while adjusting for local context; and (b) look across different neighbourhoods (while adjusting for individual level characteristics) to examine whether the effects of immigration function at the neighbourhood level.

\section{Research questions}

Given the contradictory findings of previous research three questions guide the analysis that follows.

1. Is trust in the police higher or lower among immigrants compared with nonimmigrants?

2. How does immigrants' trust in the police vary over time, particularly in relation to experiences of policing?

3. What is the effect of immigration at the neighbourhood level on trust in police?

While we are limited to a particular context, and the generalizability of our findings beyond England and Wales is doubtful, this appears a suitable 'research site' in which to address our questions. According to the 2011 Census, 13 per cent of people in England and Wales (7.5 million) were born outside the UK. The level of political debate and discord that immigration currently provokes, particularly in relation to social cohesion and trust in society, motivated our analysis. Also, the diversity of countries from which migrants to the UK originate suggests that we can and should consider migration status and ethnicity as separate variables in our analysis. We examine the association between trust and migration status while controlling for ethnicity; but we also show there are important interactions between these variables.

\section{The Study}

Data

The Crime Survey of England and Wales (CSEW) is a well-established survey that needs little introduction. ${ }^{1}$ Survey data from three years - 2008/09, 2009/10 and 2010/11 - were combined into one dataset. The CSEW fields a complex modular design wherein not all respondents are asked all questions. The full dataset used here contained 137,677 respondents, but our primary analysis relates to those 28,706 respondents who were asked a consistent set of questions about their experiences of UK policing (of these, 3,714 were born outside the UK).

We obtained a geocoded data file and added LSOA-level data from the 2011 Census to the survey data. ${ }^{2}$ LSOA stands for Lower Super Output Area, a Census 
based unit of which there are over 30,000 in England and Wales, each with a population of between 1,000 and 3,000 people. Because the CSEW uses a stratified sampling technique respondents are not spread evenly across the country but clustered within LSOAs, making multi-level modeling possible. Within the full dataset there are on average six respondents per LSOA (minimum one, maximum 50). Within the subsample that was asked questions about police contact, there are on average two respondents per LSOA.

Response variable: Trust

Debate continues about the meaning and measurement of trust. In a recent review PytlikZillig and Kimbrough (2015) note a number of issues that continue to generate disagreement within trust scholarship. These issues include: the role of risk, vulnerability and active choice in trust; the difference between trust as an attitude and trust as a process; and what type of relationship needs to exist before one can reasonably claim certain psychological and behavioural states as trust. There are, though, points of agreement, which revolve around the idea that trust:

'...involves a trustor (subject) and trustee (object) that are somehow interdependent; ... a situation containing risks for the trustor (which also implies the trustor has goals); is experienced by the trustor as voluntary (implying autonomy, agency, and intrinsic motivation); and includes (or excludes) different types, forms, or sources of trust concepts, some of which may form the bases of others, and many of which involve or relate to positive evaluations or expectations.' (ibid: 1).

In this context, trust in the police among citizens might reasonably be defined as the subjective probability of valued behaviour under conditions of uncertainty (Jackson \& Gau 2015). On this account, trust is a judgment that a trustor makes about the likelihood of a trustee following through with an expected action, with the assumption that such an attitude towards the trustee encourages trusting behaviour on the part of the trustor. Criminologists have however tended to approach trust in the police not just as a given individual's subjective judgement about the future behaviour of a police officer during a specific encounter, but also as people's judgements about how the police generally behave (see, e.g., Stoutland, 2001; Flexon et al. 2009). Here, one can infer that an individual trusts the police when that individual believes police officers have the intentions and capabilities to be fair, effective and take the interests of the public into account. We follow this approach.

The response variable is a scale created from seven survey items that asked CSEW respondents to agree or disagree with statements about the police in their local area. These items covered topics such as reliability, fairness and dealing with minor crimes. Responses were on a five point Likert-type scale. By combining responses to these items into a single scale we obtained a measure of trust that combines measures of both efficacy and right intentions. Confirmatory Factor Analysis (CFA) in the package MPlus 7.2 was used to construct, validate and extract 
this scale. Item wordings, factor loadings and fit statistics are shown in the Appendix Table (indicators were set as categorical). Note that full information maximum likelihood estimation was used, meaning that respondents who answered only some of the items were not excluded from the analysis (those who answered none were dropped). See below for more on missing data.

This approach to defining trust is consistent with all three theoretical models of trust discussed earlier. For Hardin trust is based on knowledge; on this account, citizens' understandings of police effectiveness and fairness comprises trust. Although Uslaner critiques Hardin's viewpoint that trust is based on concrete knowledge, and claims that it is a hereditable moral value, he too stresses the primacy of the beliefs people have about the intentions of others. Finally, Gidden's positions trust as faith in the ability of abstract and/or expert systems - in this case the police - to provide returns of security and justice. Whether trust arises out of personal, vicarious or other experiences, or as a result of socialization processes, peoples' perceptions about the ability of police to do their job and act fairly corresponds with all these definitions.

\section{Explanatory variables}

Our main explanatory variable, immigrant status, was entered into our models as a series of dummy variables. With the reference category fixed as 'born in the UK', separate dummy variables represented those who had arrived in the UK as children (aged under 16 years); those who had arrived as adults more than 30 years ago; as adults between 21 and 30 years ago; as adults 11-20 years ago; as adults 5-10 years ago; and as adults less than five years ago. Coding migration status in this way allowed us to explore in one model the effects of simply being an immigrant and length of stay.

Two further explanatory variables represented respondents' experiences of policing, an important factor in shaping trust: first, whether they had ever (i.e. at any point) been stopped by police, and second whether they had ever felt 'annoyed' by police. Note that the second item is much broader than the first - there are many reasons why people become annoyed with police, ranging from personal contact with officers to what they read in their newspapers: all such experiences constitute information they can use to form judgments about the ability and intentions of police. $^{3}$

The final explanatory variable - which allows us to address research question 3 (and answer questions 1 and 2 while adjusting for neighbourhood context) - was measured at the LSOA level, and comprised the proportion of

residents born in the UK. This was taken directly from the relevant Census output. The natural log was taken to correct for a heavy skew.

\section{Individual level control variables}

Individual-level control variables were age, gender, ethnicity, educational attainment, employment status, victimization status (whether the respondent had been a victim of crime in the previous 12 months), and citizenship (UK/non-UK), all 
entered as dummy variables. We also included an interval/ratio measure of respondent perceptions of neighbourhood disorder. ${ }^{4}$

\section{Area level control variables}

Three important control variables at the area (LSOA) level were included. First, a measure of deprivation was derived from factor analysis of key indicators of social deprivation (percent unemployed, percent never worked, percent lone parent households, percent of households with no car, percent living in social rented accommodation). High scores on this measure indicate a higher level of deprivation. Second, as a measure of crime we included the proportion of CSEW respondents who reported victimization in the last 12 months (using the full 137,677 sample). Third, given the emphasis in much of the literature on the association between ethnic diversity and trust we used Census data to create a measure of ethnic diversity: Hirschman's concentration index (1964), which can be interpreted as the probability that two randomly selected individuals from the same area will be of different ethnicities (Sturgis et al. 2014: 7-8). The natural log was taken to correct for skew. This measure was highly correlated with immigrant concentration, although not excessively so ( $r=-.77$ - less ethnically diverse areas tended to contain more people born in the UK). Finally, we also included dummy variables representing whether the respondent lived in London, or in an 'inner city' area.

\section{Results}

In the CSEW sample 11 per cent of respondents were born outside the UK. Bivariate analysis showed that, on average, trust in the police was significantly, although not substantially, higher among immigrants - the mean of the trust scale was .18 among the non-UK born, compared with -.03 among the UK-born $(\mathrm{t}=16.9, \mathrm{p}<.0005)$.

There was also a significant association between the number of years an immigrant had spent in the UK and mean levels of trust in the police. Table 1 summarizes the association, and shows mean levels of trust among immigrants who had been in the UK for varying lengths of time (and also among the UK born population). Note that the association between time since first arrival and trust was curvilinear - trust first fell with increasing years since initial arrival, before rising again as length of time in the UK increased further.

\section{Table 1 near here}

Not surprisingly, the time since first arrival variable was highly correlated with age $(\mathrm{r}=.80)$, such that any association between time since first arrival and trust in the police might be confounded by age. Table 1 also summarizes the association between age and trust. Trust in the police was relatively flat across early adulthood and middle age before increasing as people start to move into older age. To deal with the correlation between age and time since first arrival we therefore entered age as well as migration status into our regression models as a set of dummy variables (coded as 50-59; 60-69; 70 and over; under 50 was therefore the reference category). This design means that there were at least some immigrants in the sample who were both in the youngest age category included in the model 
(under 50) and among the group longest resident in the UK (over 30 years) - some 45 in total.

\section{Multivariate analysis}

Table 2 shows results from a series of multi-level linear regression models predicting trust in the police. Model 1 contains the control variables only. Notably, many of the ethnic group dummy variables are significant, and indicate that trust was generally higher among most minority groups than among the white majority. Two important exceptions were the black Caribbean and mixed black and white groups, where levels of trust were lower. Also, non-UK citizens appeared to trust the police more than UK citizens.

\section{Table 2 near here}

Model 2 adds the dummy variables representing immigrant status. Conditioning on the other variables in the model, immigrants expressed, on average, more trust in the police than their counterparts born in the UK, with the most recent arrivals having the highest levels of trust; by contrast, the coefficient representing those who arrived as children was much smaller and statistically insignificant: trust among this group of immigrants was essentially the same as among the native-born population. The curvilinear effect described in Table 1 is replicated: controlling for other factors, mean levels of trust among immigrants who arrived between 21 and 30 years ago were no different to the UK-born population, and significantly lower than among other immigrants. Once immigration status was included in the model, the coefficient for nationality shrank effectively to zero and lost significance, as did the coefficients for those with Black African and Indian ethnicities. The coefficient for those with Bangladeshi or Pakistani ethnicities also shrank in size. One interpretation here is that the association between nationality and trust is fully explained by immigration status, while the association between ethnicity and trust is at least partially explained by immigration status.

Model 3 in Tabale 2 adds the dummy variable representing whether a respondent had 'ever been stopped' by police, while Model 4 adds the dummy for 'ever been annoyed' by police. Absent the annoyance measure there was a negative association between contact with police and trust; but once the annoyance measure was added the 'contact' variable lost significance, while the coefficient for 'ever annoyed' was significant and strongly negative (in other words it was probably not being stopped that was in and of associated with lower levels of trust, but rather having been annoyed about what police did during the stop). Moreover 'annoyance' appears to mediate some of the relationship between years since first arrival and trust - note the changes in dummy coefficients for migration status (for the most recent arrivals it shrinks from .28 to .18, for example). This suggests that one reason why recent arrivals have more positive views is that they are yet to have (negative) experiences of police, whether those experiences be personal, vicarious or gleaned from the media. ${ }^{5}$ Conditioning on experience, the difference between immigrants and non-immigrants diminishes but does not disappear. There is a residual positive association between migrant status and trust that persists no matter how long 
people have been living in the UK and once all the other variables included in the models are taken into account.

Looking at the area level variables, across all models we find that there was no significant association between trust in police and levels of deprivation, ethnic concentration, or victimization. However, there was a significant negative association between the proportion of people in an area born in the UK and levels of trust in the police among those living there. Conditioning on personal characteristics and other neighbourhood level factors, those who lived in areas with more immigrants tended to trust the police more than people who lived in areas with less immigrants. Immigration into an area does not seem to weaken public trust in the police but, if anything, to bolster it.

Some other findings are worthy of comment. Victims, and those who perceived more disorder in their local areas, tended to express less trust in police, while women trusted police somewhat more than men. Few of the other control variables included in the models were significant - with one notable exception. While the coefficients for most ethnic minority groups lost significance once immigrant status was added to the models, those for the mixed black and white and black Caribbean groups were significant, and negative, throughout: trust in the police among these ethnic groups is consistently lower than among others.

\section{Further analysis}

There are (at least) two significant objections to the story developed so far. First, that by simply holding constant ethnicity we are, in a sense, missing the point. The experiences of immigrants in a country such as the UK are inextricably bound up with ethnicity and minority status. Most obviously, white immigrants seem likely to have different experiences of police than non-white immigrants. Moreover, in as much as ethnicity correlates with country of origin we may be glossing over important variation in the cultural experiences of policing people bring with them to their new home.

The obvious way to investigate this latter issue would be to look at respondents' country of origin, to see if people from more repressive countries of origin, for example, tend to have less trust in police. Unfortunately the publically available CSEW data files do not record country of origin. We can however use the broad ethnic group variable included in the survey as a partial proxy as well as a measure of interest in its own right. Some of the major ethnic categories in the UK map closely onto particular parts of the world. British Asian immigrants come largely from Pakistan, Bangladesh and India (with a smaller number hailing from East Africa). ${ }^{6}$ Black Caribbean immigrants come almost entirely from the Caribbean; black Africans, of course, could come from any one of the hugely diverse subSaharan African countries.

Figure 1 shows the conditional mean levels of trust in the police by years since first arrival across five different ethnic categories - the four listed above and the white group - generated by adding an interaction between ethnicity and migrant status to Model 4 in Table 2. Variation by time since first arrival was relatively stable across the different groups. Most importantly, among those who had only recently arrived in the UK mean levels of trust were consistently higher 
than the overall average (indicated by the thick horizontal line) - with one exception, the black Caribbean group. Trust in the police is higher among migrants from all groups who arrived between 5 and 20 years ago, and more than 30 years ago. Note also that mean levels of trust among people from visible ethnic minority groups born in the UK (particularly the black Caribbean group) tend to be lower than among their white counterparts.

\section{Figure 1 near here}

The second objection refers directly to Hardin's notion of trust. Recent immigrants, in particular, may not feel they have enough information on which to base their survey answers, and they may therefore be particularly likely to answer 'don't know' to questions about the police: indeed, such a response seems entirely reasonable. The pattern of missing data may thus vary by migration status, and this may affect the results described above. Yet, while analysis of the pattern of missing data across the 7 items used to construct the trust scale showed that most recent immigrants were more likely to answer don't know - 88 per cent of those who arrived in the last 5 years answered all 7 questions, compared with 94 per cent of those born in the UK - the difference was not particularly large. Only 1 per cent of those who arrived in the last 5 years responded don't know to all seven questions used in the trust scale (and those not answering any question were excluded from the analysis).

Finally, recall we found that people who lived in areas with more immigrants tended to trust the police more. An obvious question is whether this statistical effect is constant across immigrants and non-immigrants. It might be expected, prima facie, that immigrant concentration will have different effects on these different groups of people. To explore this we estimated one further model, replicating Model 4 in Table 2 but with a measure of migrant status to indicate simply whether a respondent was born in the UK, arrived as a child, or arrived as an adult. An interaction term between this measure and the LSOA-level measure of proportion born in the UK was also added. The results from this interaction are shown in Figure 2, which plots conditional mean levels of trust by immigration status and LSOA population composition.

\section{Figure 2 near here}

Figure 2 shows that among both migrant and non-migrant groups, trust in the police is higher in areas with greater proportions of non-UK born residents. Levels of trust diminish as the proportion of UK-born residents increases. In other words, even among the native-born population trust in the police is higher, on average, in areas where there are more immigrants. It is difficult to glean a reason for this statistical effect from the data at hand, and suffice to say more work is needed to unpick such a finding.

\section{Discussion and conclusions}


To return to our original research questions, we find that trust in the police is on average higher among immigrants to the UK than among the UK-born population (question 1). It appears that some of this difference is due to a lack of experience of the police among the recently arrived. Once experience was taken into account, the difference between immigrants and non-immigrants shrinks, but there was a persistent association between immigrant status and trust, among those who arrived as adults, that was not 'explained away' by other variables included in our models. By contrast, those who arrived as children had essentially the same views, on average, as their UK-born counterparts. We also find that trust in the police was higher among people who lived in areas with larger immigrant populations (question 3).

The answer to question 2 is more complicated. Levels of trust among recent arrivals were higher than among UK-born respondents or people who had migrated longer ago, suggesting an acculturation process does occur (Berry 1997). However the curvilinear association between years since first arrival and trust, which persists once other variables are taken into account, remains a puzzle. Why are immigrants who have been in the UK for 21-30 years less trusting of police than those who arrived before or after? One tempting suggestion is that these are people who arrived in the UK in the 1980s, which was a particularly difficult time for British policing; the era of the Brixton riots, the miner's strike, the Hillsborough stadium disaster and many other policing scandals. While we can only speculate, it may be that people who arrived into a climate where the relationship between police and the public was under particular strain 'carried forward' their first perceptions of the police formed at this time. It is moreover notable that it was within the black ethnic groups that trust was lowest in this cohort of immigrants (see Figure 2).

These findings have implications for our understandings of trust in the police. We framed the analysis here with discussion of three different theories of trust, and while we did not set out to test these theories, it is instructive to compare our findings against them. All three suggest a conception of trust that revolves around perceptions of the effectiveness and, in particular, good intentions of police. But each has different implications in terms of the dynamics of trust among immigrant populations, and of the three our data seem to fit most closely with Giddens' notion that trust is a complexity reducing mechanism that enables action and is, because it is developed during childhood, unevenly distributed across populations. It does not seem unreasonable to suggest that immigrants will on average be higher in such trust than non-immigrants: a high level of trust in abstract systems may be one factor that enables the choice to migrate (for those who have that choice). The finding that those who arrived in the UK as children did not trust the police more than the UK-born sample offers support for this argument - they will not (usually) have made a choice to migrate. Our data also correspond with some aspects of Uslaner's theory of trust. It seems reasonable to suggest, for reasons similar to those above, that migrants will be more likely to be moralistic trustors and thus predisposed to trust. However, the CSEW data fit less well with Uslaner's emphasis on the importance of shared community in the generation of 
trust relationships, particularly in as much as recently arrived migrants tended, overall, to express the highest levels of trust.

Out data also seem to fit less well with Hardin's emphasis on the importance of concrete personal knowledge in driving the perceptions that constitute trust. Those least likely to have such knowledge in relation to the police - recently arrived immigrants - were the most likely to indicate trust. As found by many other studies, however, our models reiterated that personal and vicarious experiences are important in shaping trust - the 'ever annoyed' variable was perhaps the strongest predictor of trust - albeit that the lack of experience of (British) police among recent immigrants was one factor accounting for their higher levels of trust; once this was taken into account the differential between immigrants and nonimmigrants shrank.

The overall picture seems, then, to be of a 'leap of faith'. Immigrants, when faced with questions about the British police, seem more inclined than others to indicate a belief that police do have the right intentions and are competent in the roles assigned to them. One reason for this might well be that it is reassuring to orient oneself toward important institutions in this manner. Another may be that believing the police are competent and well-intentioned enables activity that might otherwise be curtailed.

What might encourage immigrants to make this leap of faith? One possibility is that British policing has a strong brand image with an arguably worldwide reach. This image, wrapped up with 'Scotland Yard', the bobby on the beat and notions of fairness and equity, may provide people who have recently moved to the UK with a heuristic on which to base their trust judgments. It is easier to make a leap of faith if one thinks one already knows something positive about the trust object. Yet, there is reflexivity in this relationship, and immigrants, as do others, refine their opinions in the face of experience. Indeed, there is an element almost of tragedy in our results. While trust in the police may be high among first generation immigrants from visible minority groups, for members of the same groups born in the UK it is no higher, and in some cases lower, than among the UK-born white majority (see also Heath et al. 2011). It seems that poor policing of (some) ethnic minority groups squanders the positive levels of trust among many immigrants when they first arrive in the UK.

There are important caveats to be drawn around these findings. First, we have relied on secondary analysis of the CSEW. While this is a high quality survey which maintains good response rates (76\% in 2009/10, for example) it has important limitations. Perhaps most obviously the sample is unlikely to include many irregular migrants, and our findings here probably relate only to those with a regular immigration status. Our analysis is also limited by the cross-sectional nature of the survey (we cannot model processes of change) and its inability to measure actual behavior - a point that leads directly to the second main limitation of this paper.

Our measure of trust relies on answers to survey questions: what Li (2015) calls 'trust as attitude', a set of beliefs or understandings that the trustor holds in relation to the trustee. What we have not measured is 'trust as choice' (ibid.) - the willingness to act in such a way as to make oneself vulnerable to the trustee. On this 
account attitudes are a necessary but insufficient measure of trust. Also required is an understanding of people's propensities to behave in ways that place important outcomes at the mercy of others. We might, for example, suggest that people's willingness to report crime to the police, or to provide information and act as witnesses, will express trust as choice. More research is needed to address these issues. Are immigrants more willing than others to engage with police, report crime, or to cooperate with police in other ways - that is, to demonstrate trust as choice? If they are not, it will be necessary to explore the barriers that may obstruct or prevent attitudes translating into choices.

Third, it seems almost certain that when immigrants, particularly recent arrivals, are asked to think about the British police they make implicit or explicit comparisons with police in their country of origin. Given the nature of policing in many parts of the world the British police may appear more professional, effective and better intentioned than would otherwise be the case. The greater the proportion of immigrants with backgrounds in countries with unprofessional and ineffective police, then, the higher trust in the police in the UK will appear to be.

These caveats raise important questions in relation to the way trust in the police is conceptualized and operationalized in criminological research. How different would the results above look if we had measured trust as choice as well as attitude? Equally, the idea that trust in police may be comparative is worthy of further consideration, and underlines that trust in institutions such as the police is a changeable construct, open to influence from many different sources and likely to be shaped by multiple factors as people move through their lives.

All that said, our findings contain an important message. Contrary to commonsense views of the relationship between immigration and trust, it seems that in England and Wales trust in the police tends to be higher among immigrants. It is also higher, on average, among people living in areas with more immigrants, regardless of whether they were born in the UK or not. Resonating with other recent studies in cognate areas (e.g. Sturgis et al. 2014; MacDonald et al. 2013), our results call into question the widespread assumption that immigration (at least into the UK) renders the relationship between police and public more difficult or problematic.

\section{Footnotes}


1. See http://www.ons.gov.uk/ons/guide-method/method-quality/specific/crimestatistics-methodology/guide-to-finding-crime-statistics/crime-survey-forengland-and-wales--csew-/index.html (accessed November 2015).

2 . The Census data thus relate to the very end of the period covered by the survey data. On balance we do not believe this will introduce significant bias into the analysis.

3. Note we are assuming that respondents who migrated to the UK refer in these questions to British police and not those in their countries of origin, which seems reasonable given the emphasis in the CSEW on local policing and the British criminal justice system.

4. A factor score reflecting views on 'how much of a problem' various forms of lowlevel disorder were in respondents' local areas, coded such that high scores indicated seeing disorder as more of a problem.

$5.6 \%$ of those who arrived in the UK in the last 5 years reported having ever been annoyed with police, compared with $14 \%$ of migrants who arrived more than 30 years ago, $27 \%$ of migrants who arrived in the UK as children, and $26 \%$ of those born in the UK.

6. Muslim respondents with Indian ethnicities were included in the Pakistani/Bangladeshi category: their experience of policing in the post 9-11 world may be shaped by the religion they share with these latter groups.

\section{References}

Alesina, A., \& La Ferrara, E. (2002). Who trusts others? Journal of Public Economics, $85,207-234$.

Berry, J. (1997). Immigration, Acculturation, and Adaptation. Applied Psychology, 46(1): 5-34.

Brown, B., and Benedict, W.R. (2002). Perceptions of the police: Past findings, methodological issues, conceptual issues and policy implications. Policing: An International Journal of Police Strategies \& Management 25: 543-580.

Crepaz, M.M.L. (2008). Trust Beyond Borders: Immigration, the Welfare State and Identity in Modern Politics. University of Michigan State.

Davis, R., \& Hendricks, M. (2007). Immigrant and the law enforcement: A comparison of native-born and foreign-born Americans' opinions of the police. International Review of Victimology, 14(1), 81-94.

Davis, R., \& Mateu-Gelabert, P. (2000). Effective police management affects citizen perceptions. National Institute of Justice Journal, 7, 24-25.

Delsol, R. \& Shiner, M. (2015). Stop and Search: The Anatomy of a Police Power. London: Palgrave Macmillan. 
Dinesen, P. T. (2013). Where you come from or where you live? Examining the cultural and institutional explanation of generalized trust using migration as a natural experiment. European Sociological Review, 29(1), 114-128.

Flexon, J. L., Lurigio, A. J., \& Greenleaf, R. G. (2009). Exploring the dimensions of trust in the police among Chicago juveniles. Journal of Criminal Justice, 37, 180-189.

Giddens, A. (1991). Modernity and Self-Identity. Cambridge: Polity Press

Girling, E., Loader, I. and Sparks, R. (2000). Crime and Social Change in Middle England: Questions of Order in an English Town. London: Routledge.

Goodhart, D. (2004) Discomfort of Strangers. Available at http://www.theguardian.com/politics/2004/feb/24/race.eu (accessed 18th November 2015).

Hardin, R. (2006). Trust and Trustworthiness. New York: Russel Sage Foundation.

Heath, A.F., Fisher, S.D., Rosenblatt, G., Sanders, D and Sobolewska, M. (2011) The Political Integration of Ethnic Minorities in Britain. Oxford: Oxford University Press.

Jackson, J. and Sunshine, J. (2007). 'Public Confidence in Policing: A NeoDurkheimian Perspective', British Journal of Criminology, 47, 2, 214-233.

Jackson J, Bradford B, Stanko B and Hohl K (2013) Just authority? Trust in the police in England and Wales. London: Routledge.

Jackson, J. and Gau, J. (2015). 'Carving up Concepts? Differentiating between Trust and Legitimacy in Public Attitudes towards Legal Authority', in Shockley, E. et al. (eds.) Interdisciplinary Perspectives on Trust: Towards Theoretical and Methodological Integration. New York: Springer, pp. 49-69.

Li, P.P. (2015) Trust as a Leap of Hope for Transaction Value: A Two-Way Street Above and Beyond Trust Propensity and Expected Trustworthiness, in Bornstein, B.H. and Tomkins, A.J. (eds) Motivating Cooperation and Compliance with Authority: The Role of Institutional Trust. Cham: Springer, pp.37-54.

MacDonald, J.M., Hipp, J.R. and Gill, C. (2013) The Effects of Immigrant Concentration on Changes in Neighborhood Crime Rates. Journal of Quantitative Criminology 29: 191-215.

Maxwell, R. (2010) Trust in Government Among British Muslims: The Importance of Migration Status. Political Behaviour 32(1): 89-109. 
McLaren, L.M. (2010) Cause for Concern? The Impacgt of Immigration on Political Trust. London: Policy Network.

Montinola, G.R. (2004) Corruption, Distrust and the Deterioration of the Rule of Law, in Hardin R. (ed) Distrust. New York: Russell Sage Foundation, pp.298-324. Möllering, G. (2006) Trust: Reason, Routine and Reflexivity. Oxford: Elsevier.

Murphy K and Cherney A (2012) Understanding cooperation with police in a diverse society. British Journal of Criminology 52(1): 181-201.

Mutsaers, P. (2014) An Ethnographic Study of the Policing of Internal Borders in the Netherlands: Synergies Between Criminology and Anthropology. British Journal of Criminology 54(5): 831-848.

Nannestad, P., Svendsen, G.T., Dinesen, P.T and Sønderskov, K.M. (2014) Do Institutions or Culture Determine the Level of Social Trust? The Natural Experiment of Migration from Non-western to Western Countries. Journal of Ethnic and Migration Studies 40(4): 544-565.

Pantazis, C. and Pemberton, S. (2009) From the 'Old' to the 'New' Suspect Community. Examining the Impacts of Recent UK Counter-Terrorist Legislation. British Journal of Criminology 49(5): 646-666.

Parmar, A. (2011) Stop and Search in London: Counter-Terrorist or CounterProductive? Policing and Society 21(4): 369-382.

Piatkowska, S. J. (2015). Immigrants ' confidence in police : do country-level characteristics matter? International Journal of Comparative and Applied Criminal Justice 39(1): 1-30.

Polanyi, M. (1967), The Tacit Dimension. New York: Anchor Books.

Putnam, R. (2007) E Pluribus Unum: Diversity and Community in the Twenty-first Century The 2006 Johan Skytte Prize Lecture. Scandinavian Political Studies 30(2): 137-174.

PytlikZillig, L. M. and KJimbrough, C. D. (2015). 'Consensus on Conceptualizations and Definitions of Trust: Are We There Yet?', in Shockley, E., Neal, T. M. S., PytlikZillig, L. and Bornstein, B. (eds.) Interdisciplinary Perspectives on Trust: Towards Theoretical and Methodological Integration. New York: Springer, pp. 17-47.

Röder, A. and Mühlau, P. (2012) What determines the trust of immigrants in criminal justice systems in Europe? European Journal of Criminology 9(4): 370-387.

Sampson, R. (2008) Rethinking Crime and Immigration. Contexts Winter 2008: 2833. 
Sharp, D., \& Atherton, S. (2007). To Serve and Protect?: The Experiences of Policing in the Community of Young People from Black and Other Ethnic Minority Groups. British Journal of Criminology, 47(5), 746-763.

Smith, D. (2007). The Foundations of Legitimacy, in Tyler, T.R. (ed) Legitimacy and Criminal Justice: International Perspectives, 30-58. New York: Russell Sage Foundation.

Stoutland, S. (2001). The multiple dimensions of trust in resident/police relations in Boston. Journal of Research in Crime and Delinquency, 38, 226-256.

Sturgis, P., Brunton-Smith, I., Kuha, J., \& Jackson, J. (2014). Ethnic diversity, segregation and the social cohesion of neighbourhoods in London. Ethnic and Racial Studies, 37(8), 1286-1309.

Thomas, P.M. (2011) Theoretical Articulation on Homicide and Crime. Homicide Studies 15(4): 382-403.

Tyler T.R. (2005) Policing in black and white: Ethnic group differences in trust and confidence in the police. Police Quarterly 8(3): 322-342.

Tyler, T.R. and Huo, Y.J. (2002) Trust in the Law. New York: Russell Sage Foundation.

Uslaner, E.M. (2002). The Moral Foundations of Trust. Cambridge: Cambridge University Press.

Uslaner, E.M. (2008). Where You Stand Depends Upon Where Your Grandparents Sat: The Inheritability of Generalized Trust. Public Opinion Quarterly 72(4): 725740 . 
Table 1: Trust in the police: by migration status and age

\begin{tabular}{lrr}
\hline & Mean & SD \\
\hline Migration status & & \\
Born in UK & -0.03 & 0.72 \\
Arrived as a child & 0.00 & 0.73 \\
Arrived > 30 years ago & 0.20 & 0.69 \\
Arrived 21-30 years ago & 0.09 & 0.70 \\
Arrived 11-20 years ago & 0.20 & 0.76 \\
Arrived 5-10 years ago & 0.29 & 0.71 \\
Arrived less than 5 years ago & 0.31 & 0.67 \\
& & \\
Age & & \\
$16-19$ & & \\
$20-29$ & -0.04 & 0.82 \\
30-39 & -0.03 & 0.77 \\
$40-49$ & 0.02 & 0.73 \\
$50-59$ & -0.04 & 0.72 \\
$60-69$ & -0.09 & 0.71 \\
70 and over & -0.04 & 0.69 \\
& 0.12 & 0.67 \\
All people & & \\
\hline
\end{tabular}


Table 2: Results from multi-level linear regression models predicting trust in the police

\begin{tabular}{|c|c|c|c|c|c|c|c|c|}
\hline & \multicolumn{2}{|c|}{ Model 1} & \multicolumn{2}{|c|}{ Model 2} & \multicolumn{2}{|c|}{ Model 3} & \multicolumn{2}{|c|}{ Model 4} \\
\hline & B & $\mathrm{se}(ß)$ & B & $\mathrm{se}(ß)$ & B & $\mathrm{se}(ß)$ & ß & $\mathrm{se}(ß)$ \\
\hline \multicolumn{9}{|l|}{ Survey year (ref: 2008/09) } \\
\hline 2009/10 & $0.02^{*}$ & -0.01 & $0.02 *$ & -0.01 & $0.02^{*}$ & -0.01 & $0.03^{* *}$ & -0.01 \\
\hline 2010/11 & $0.06^{* * *}$ & -0.01 & $0.06^{* * *}$ & -0.01 & $0.06^{* * *}$ & -0.01 & $0.06^{* * *}$ & -0.01 \\
\hline \multicolumn{9}{|l|}{ LSOA level measures } \\
\hline Deprivation & 0.01 & -0.01 & 0.01 & -0.01 & 0 & -0.01 & 0 & -0.01 \\
\hline Crime (CSEW victimization rate) & 0.01 & -0.02 & 0.01 & -0.02 & 0.01 & -0.02 & 0.01 & -0.02 \\
\hline \% born in the UK (logged) & $-0.18 * * *$ & -0.05 & $-0.16 * *$ & -0.05 & $-0.16^{* *}$ & -0.05 & $-0.14 * *$ & -0.05 \\
\hline Ethnic concentration (logged) & 0 & -0.01 & 0 & -0.01 & 0 & -0.01 & 0 & -0.01 \\
\hline \multicolumn{9}{|l|}{ Area type (ref: others) } \\
\hline Inner city & -0.01 & -0.02 & -0.01 & -0.02 & -0.01 & -0.02 & 0 & -0.02 \\
\hline \multicolumn{9}{|l|}{ Lives in London (ref: no) } \\
\hline London & -0.01 & -0.02 & -0.02 & -0.02 & -0.02 & -0.02 & -0.02 & -0.02 \\
\hline \multicolumn{9}{|l|}{ Individual level measures } \\
\hline \multicolumn{9}{|l|}{ Age (ref: below 50) } \\
\hline $50-59$ & $-0.06 * * *$ & -0.01 & $-0.06 * * *$ & -0.01 & $-0.06 * * *$ & -0.01 & $-0.07^{* * *}$ & -0.01 \\
\hline $60-69$ & $-0.05 * * *$ & -0.01 & $-0.05 * * *$ & -0.01 & $-0.05 * * *$ & -0.01 & $-0.07 * * *$ & -0.01 \\
\hline 70 plus & $0.06^{* * *}$ & -0.02 & $0.06^{* * *}$ & -0.02 & $0.05^{* *}$ & -0.02 & 0 & -0.01 \\
\hline \multicolumn{9}{|l|}{ Gender (ref: male) } \\
\hline Female & $0.12^{* * *}$ & -0.01 & $0.12^{* * *}$ & -0.01 & $0.11^{* * *}$ & -0.01 & $0.09^{* * *}$ & -0.01 \\
\hline \multicolumn{9}{|l|}{ Victim of crime (ref: no) } \\
\hline Victim & $-0.08 * * *$ & -0.01 & $-0.08 * * *$ & -0.01 & $-0.08 * * *$ & -0.01 & $-0.05 * * *$ & -0.01 \\
\hline Perception of disorder (high=more) & $-0.27 * * *$ & -0.01 & $-0.27 * * *$ & -0.01 & $-0.27 * * *$ & -0.01 & $-0.24 * * *$ & -0.01 \\
\hline \multicolumn{9}{|l|}{ UK National (ref: Yes) } \\
\hline Non-UK national & $0.18^{* * *}$ & -0.02 & 0.01 & -0.03 & 0 & -0.03 & 0 & -0.03 \\
\hline \multicolumn{9}{|l|}{ Ethnic group (ref: White) } \\
\hline Bangladeshi/Pakistani & $0.15^{* * *}$ & -0.04 & $0.09^{*}$ & -0.04 & $0.08^{*}$ & -0.04 & 0.07 & -0.04 \\
\hline Black African & $0.10^{*}$ & -0.04 & 0.02 & -0.05 & 0.02 & -0.05 & 0.04 & -0.04 \\
\hline Black Caribbean & $-0.16 * * *$ & -0.04 & $-0.20 * * *$ & -0.04 & $-0.20 * * *$ & -0.04 & $-0.14 * * *$ & -0.04 \\
\hline Indian & $0.13^{* * *}$ & -0.03 & 0.06 & -0.03 & 0.05 & -0.03 & 0.05 & -0.03 \\
\hline Mixed White and Black & $-0.25 * * *$ & -0.07 & $-0.26 * * *$ & -0.07 & $-0.26 * * *$ & -0.07 & $-0.20^{* *}$ & -0.07 \\
\hline Mixed other & 0.09 & -0.07 & 0.05 & -0.07 & 0.06 & -0.07 & 0.08 & -0.07 \\
\hline Other ethnic group & $0.10^{*}$ & -0.04 & 0.04 & -0.04 & 0.04 & -0.04 & 0.05 & -0.04 \\
\hline \multicolumn{9}{|c|}{ Time since first arrival in UK (ref: born in UK) } \\
\hline Arrived as a child & & & 0.04 & -0.03 & 0.04 & -0.03 & 0.03 & -0.03 \\
\hline 30 years or more & & & $0.19^{* * *}$ & -0.03 & $0.18^{* * *}$ & -0.03 & $0.16^{* * *}$ & -0.03 \\
\hline $21-30$ years & & & 0.08 & -0.06 & 0.08 & -0.06 & 0.02 & -0.05 \\
\hline $11-20$ years & & & $0.25^{* * *}$ & -0.04 & $0.24^{* * *}$ & -0.04 & $0.19 * * *$ & -0.04 \\
\hline $5-10$ years & & & $0.26^{* * *}$ & -0.04 & $0.25^{* * *}$ & -0.04 & $0.19 * * *$ & -0.04 \\
\hline
\end{tabular}




\begin{tabular}{|c|c|c|c|c|c|c|c|c|}
\hline \multicolumn{3}{|l|}{ Less than five years } & $0.28^{* * *}$ & -0.04 & $0.26^{* * *}$ & -0.04 & $0.18^{* * *}$ & -0.04 \\
\hline \multicolumn{9}{|c|}{ Ever been stopped by police (ref: no) } \\
\hline Stopped & & & & & $-0.07 * * *$ & -0.01 & 0 & -0.01 \\
\hline \multicolumn{9}{|c|}{ Ever been annoyed by police (ref: no) } \\
\hline Annoyed & & & & & & & $-0.42^{* * *}$ & -0.01 \\
\hline Constant & $0.73^{* *}$ & -0.23 & $0.64^{* *}$ & -0.23 & $0.68^{* *}$ & -0.23 & $0.66 * *$ & -0.22 \\
\hline ICC & 0.03 & & 0.02 & & 0.02 & & 0.03 & \\
\hline $\mathrm{n}$ & 27,382 & & 27,382 & & 27,382 & & 27,382 & \\
\hline
\end{tabular}

$* \mathrm{p}<0.05,{ }^{* *} \mathrm{p}<0.01,{ }^{* * *} \mathrm{p}<0.001$

Coefficients for education and employment status omitted for brevity - none were significant in any model. 
Figure 1: Trust in the police by migration status and ethnicity

Fitted values generated from multi-level linear regression model

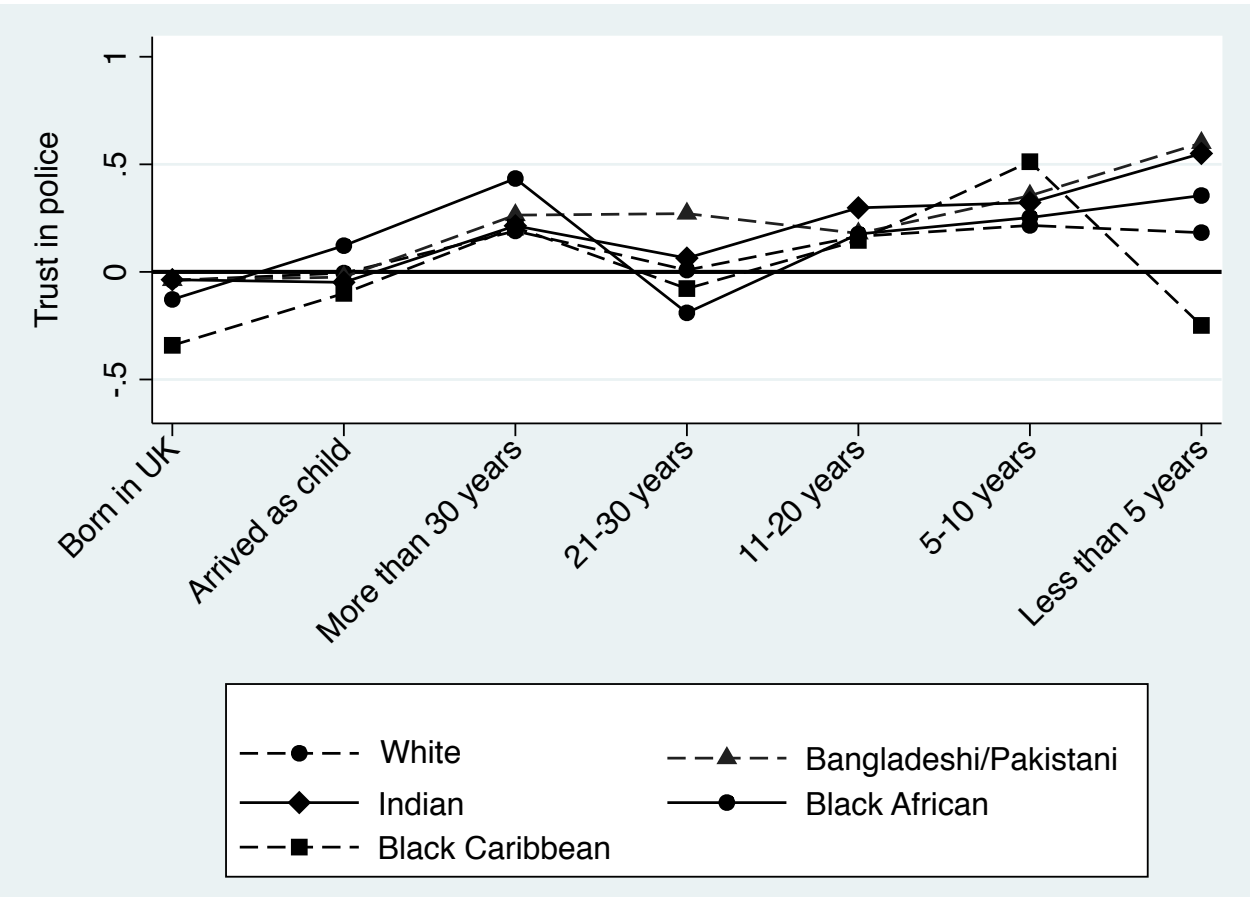


Figure 2: Trust in the police by migration status and immigrant concentration in $\mathrm{LSOA}$ of residence

Fitted values generated from multi-level linear regression model

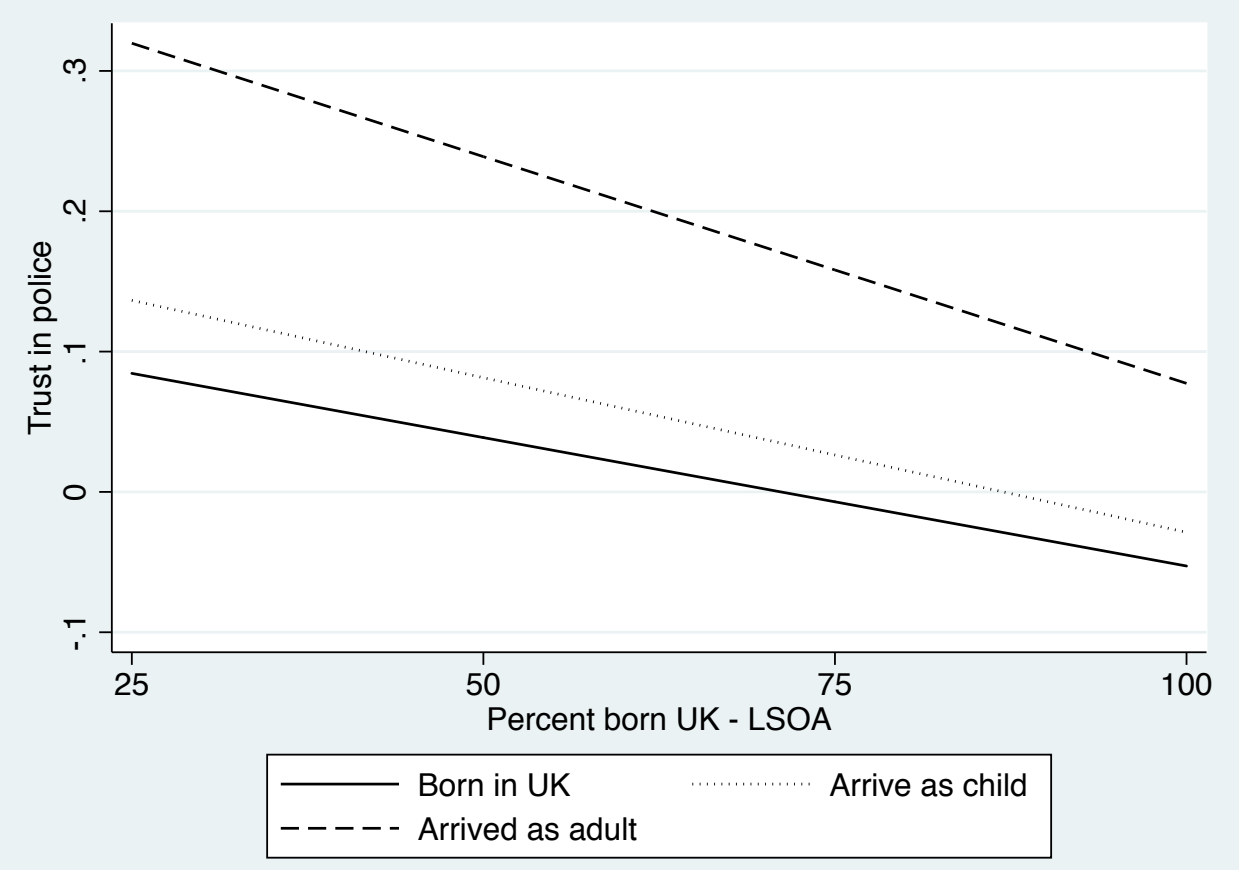




\section{Appendix Table 1: Trust in the police}

Standardized factor loadings, $\mathrm{R}^{2}$ values and fit statistics from a one-factor CFA solution

\begin{tabular}{|c|c|c|}
\hline $\begin{array}{l}\text { How much (do) you agree or disagree with each of the following } \\
\text { statements about the police in your local area? }\end{array}$ & $\begin{array}{r}\text { Std. Factor } \\
\text { loading }\end{array}$ & $R^{2}$ \\
\hline$\ldots$ can be relied upon to be there when you need them & 0.74 & 0.54 \\
\hline ... would treat you with respect if you had contact with them & 0.67 & 0.45 \\
\hline ... treat everyone fairly regardless of who they are & 0.66 & 0.44 \\
\hline ... can be relied on to deal with minor crimes & 0.73 & 0.53 \\
\hline$\ldots$ understand the issues that affect this community & 0.77 & 0.59 \\
\hline$\ldots$ are dealing with the things that matter to people in this community & 0.84 & 0.70 \\
\hline $\begin{array}{l}\text { Taking everything into account I have confidence in the police in this } \\
\text { area }\end{array}$ & 0.92 & 0.85 \\
\hline Chi2 & 1249.3 & \\
\hline Degrees of freedom & 9.00 & \\
\hline $\mathrm{p}$ value & $<0.00005$ & \\
\hline RMSEA & 0.06 & \\
\hline $\mathrm{CFI}$ & 0.99 & \\
\hline TLI & 0.99 & \\
\hline
\end{tabular}

